\section{Investing in mental health research and}

\section{development}

\author{
ILONA BLUE and TRUDY HARPHAM
}

In late 1996 the World Health Organization (WHO) published a report written by the Ad Hoc Committee on Health Research Relating to Future Intervention Options entitled Investing in Health Research and Development (WHO, 1996). In essence it was a follow-up to the World Development Report (1993): Investing in Health (World Bank, 1993), which was discussed in an editorial in this journal (Blue \& Harpham, 1994). Deep in the appendices of the 1993 report the burden of mental ill-health was revealed. Despite this, there was little attention devoted to mental health issues in the text of the World Development Report and no specific recommendations as to how to combat the problem were made. This paper attempts to shed light on the extent to which the follow-up report (WHO, 1996) addresses the current and predicted burden of mental ill-health.

\section{INVESTING IN HEALTH RESEARCH AND DEVELOPMENT}

Using identical methods to those employed in the 1993 World Development Report, the 1996 WHO report presented predictions of the global burden of disease ${ }^{1}$ for 2020. The report focused on developing countries, as this is where the bulk of the world's disease burden occurs and it concluded that one of the four key challenges such regions face is the emerging epidemics of non-communicable diseases and injuries. The report stated that ageing populations and exposure to certain risk factors are largely responsible for the growing impact of heart disease, mental illnesses, cancers, strokes and chronic respiratory diseases. In 1990 non-communicable diseases accounted for around $41 \%$ of the global

1. For a full description of the methods employed in the global burden of disease analysis see Murray \& Lopez (1994). disease burden. By 2020 it is predicted that these conditions will account for $60 \%$ of the disease burden and it is in low- and middle-income countries that the rise in the impact of non-communicable diseases will be steepest. These problems are neglected in developing countries even though their current contribution to the disease burden is considerable. That this contribution will grow in places where governments, communities and health services are unprepared is of great concern.

Within the information on non-communicable diseases, the WHO (1996) report goes some way towards highlighting the singularly large burden associated with mental ill-health. It is stated that by 2020 neurological conditions are expected to account for $15 \%$ of the total burden of disease and unipolar depression is set to become "the leading cause of disease burden in the developing regions" (WHO, 1996, p. 58). Clearly, mental ill-health was accorded a higher profile than in the World Bank's (1993) report. However, for those familiar with the small print in the latter report, the above estimates are not surprising. What is interesting is not to have fears of the growing burden of mental ill-health in developing countries confirmed, but to find out what recommendations for action were made. The 1996 WHO report suggested that health professionals should identify why a particular disease burden persists from a list of three main reasons: (a) a lack of knowledge about the disease and its determinants, (b) a lack of tools (for interventions), or (c) failure to use existing tools efficiently.

\section{LACK OF KNOWLEDGE ABOUT THE DISEASE ANDITS DETERMINANTS}

Despite the fact that lack of knowledge about the disease and its determinants is considered in the WHO (1996) report as being partly responsible for the continuing and growing burden of neurological and psychiatric conditions, no mention is made of the particular gaps in knowledge about mental ill-health that need to be filled. By failing to elaborate on the type of information required the report does little to enhance progress in this area.

There already exists a solid foundation of data on mental ill-health in developing countries, especially in relation to the prevalence of mental ill-health in community and primary health care settings using internationally validated instruments of assessment (WHO, 1994; Ustun \& Sartorius, 1995). The cross-cultural similarity of symptoms of depression has been documented (Ormel et al, 1994; Pretorius, 1995). We also know that common mental disorders account for the majority of cases of mental ill-health, and determinants include a wide variety of social and environmental factors (Cheng, 1989; Ekblad, 1993). Research into long-term difficulties and life events has been undertaken in a number of locations, although particular countries dominate the contribution to this knowledge, for example Brazil and India and certain African countries (e.g. Chakabroty, 1990; Coutinho et al, 1996; Broadhead \& Abas, 1998). However, there is limited information related to social support in developing countries. Other gaps in our understanding of the determinants of mental ill-health also exist; for example, the influence on mental health of communitylevel factors, such as high levels of violence or low levels of social cohesion, remains largely unexplored.

\section{LACK OF TOOLS}

A lack of tools was not considered responsible for the continuing and growing burden of mental ill-health in the WHO (1996) report. This is probably because work has been done in relation to the incorporation of a mental health component into primary health care in developing countries (WHO, 1990). However, we know that the majority of people suffering from mental disorders do not seek care from health services. Only a small proportion reach primary services and even fewer find their way to secondary and tertiary levels of care (Goldberg \& Huxley, 1992). Intervening at the community level is, therefore, vital so that the majority of people with mental health problems can 
be targeted. This fact was reflected by Desjarlais et al (1995), who highlighted the global and local social forces that have an impact on mental health. They emphasised the need for intervention at public policy, community and health service levels. The neglect of the need for generating community-based interventions in the WHO (1996) report is disheartening, although understandable given the difficulty of evaluating community-based interventions. However, short of widespread structural socio-economic reform, community-based interventions for mental illhealth offer a potentially effective way of tackling the problem, and further research into cost-effective interventions at this level should be considered a priority.

\section{FAILURE TO USE EXISTING TOOLS EFFICIENTLY}

The authors of the 1996 WHO report considered the failure to use existing tools efficiently a problem for mental health. Studies that have demonstrated the low rates of recognition of mental ill-health among primary care professionals were cited (Ustun \& Sartorius, 1995) and it was suggested that health workers' awareness and knowledge of mental ill-health should be increased so that existing, available treatments reach those in need. Apart from the suggestions related to improving recognition and treatment of mental illhealth at the primary health care level (a theme with which this journal is familiar (Abas et al, 1994)), there are no other hints as to what public health professionals should do to tackle the problem. There is no consideration of interventions that traditionally lie within other domains, for example the social sector, but have an influence on mental health. The need for multi-disciplinary approaches was brought up by Desjarlais et al (1995), but the focus of the 1996 WHO report once again lay squarely on health service issues.

\section{TACKLING MENTAL ILL- HEALTH IN DEVELOPING COUNTRIES}

It has been suggested that multi-disciplinary teams working with communities and governments in developing countries are needed for the implementation and evalua-

LLONA BLUE, BA, TRUDY HARPHAM, PhD, South Bank University, London

Correspondence: Ms Ilona Blue, South Bank University, School of Urban Development and Policy, Faculty of the Built Environment, 202 Wandsworth Road, London SW8 2JZ

(First received 23 July 1997. final revision 7 November 1997, accepted II November 1997)

tion of locally acceptable interventions designed to reduce mental ill-health (Abas et al, 1994). However, for such programmes to be implemented effectively health and social sector professionals need to plan and implement interventions together. There are a handful of examples where such strategies are being pursued (for example in Harare (Abas et al, 1994), in Karachi (Aga Khan University, 1997) and in Santiago (Blue et al, 1995)) and it is imperative that they be evaluated so that lessons can be learnt and progress made. Interventions being implemented include counselling services available in the community, income-generating schemes, cooperative cooking ventures for low-income women and awareness-raising campaigns related to mental ill-health.

The publication of the 1996 WHO report highlighted two issues that need to be addressed. First, despite the growing recognition of the burden of mental illhealth in developing countries, it is still the 'big killers' that command the majority of attention and funding. Second, by advocating intervention at the health service level the WHO report does not go far enough: widespread support for further research into community-based interventions encompassing the social determinants of mental ill-health is also required. It is time for the international public health community to come to terms with the fact that tackling mental ill-health in developing countries will require new interventions that relate to the social and environmental causes frequently implicated in cases of common mental disorders.

\section{REFERENCES}

Abas, M., Broadhead, J. C., Mbape, P., ot ol (1994) Defeating depression in the developing world: $a$ Zimbabwean model. One country's response to the challenge. British journal of Psychiatry. 164, 293-296.

Aga Khan University (1997) Urbon Heolth Project; Revised Proposol. Karachi: Community Health Sciences Department. Aga Khan University.
Blue, I. \& Marpham, T. (1994) The World Bank World Development Report 1993: Investing in Heolth. Reveals the burden of common mental disorders, but ignores its implications. British journal of Psychiotry. 165, 9-12.

-, Ducci, M. E., Jaswal, S., et al (1995) The mental health of low-income urban women: case studies from Bombay, India; Olinda. Brazili and Santiago. Chile. In Urbonizotion and Mental Heolth in Developing Countries (eds T. Harpham \& 1. Blue), pp. 75-101. Aldershot: Ashgate Publishing.

Broadhead, J. C. \& Abas, M. (1998) Life events, difficulties and depression among women in an urban setting in Zimbabwe. Psychologicol Medicine, 28. 29-38.

Chakabroty, A. (1990) Social Stress and Mentol Heolth: A Sociol-Psychiotric Field Study of Colcutto. London: Sage.

Cheng, T. A. (1989) Urbanization and minor psychiatric morbidity: a community study in Taiwan. Social Psychiatry and Psychiotric Epidemiology, 24, 309-316

Coutinho, E., Almeida-Filho, A., Marl, J. J., et of (1996) Minor psychiatric morbidity and internal migration in Brazil. Sociol Psychiotry and Psychiotric Epidemiology, 31. 173-179.

Desjarlais, R., Eisenberg, L., Good, B., et al (1995) World Mental Health: Problems and Priorities in LowIncome Countries. New York: Oxford University Press.

Ekbald, S. (1993) Stressful environments and their effects on quality of life in third world cities. Environment and Urbanizotion, 5, 125-134

Goldberg, D. \& Huxley, P. (1992) Common Mental Disorders: A Bio-Social Perspective. London: Routledge.

Murray, C. J. L. \& Loper, A. D. (1994) Quantifying the burden of disability: data, methods and results. Bulletin of the World Heolth Orgonizotion, 72, 481-494.

Ormel, J., VonKroff, B., Ustun, S., et al (1994)

Common mental disorders and disability across cultures. Journol of the American Medical Associotion. 272. $174 \mid-1748$.

Pretorius, W. (1995) Mental disorders and disability across cultures: a view from South Africa. Loncet, 345 534.

Ustun, T. B. \& Sartorius, N. (eds) (1995) Mentol Illness in General Health Care: An Internotional Study. Chichester: Wiley.

World Health Organization (1990) The introduction of a Mental Health Component into Primary Health Core. Geneva: WHO

- (1994) A User's Guide to the Self Reporting Questionnoire (SRQ). Geneva: WHO.

- (1996) Investing in Health Research and Development: Report of the Ad Hoc Committee on Health Reseorch Reloting to future Intervention Options, Geneva: WHO.

World Bank (1993) World Development Report 1993 Investing in Heolth. Oxford: Oxford University Press. 